\title{
Examining the relationship between anxiety and depression and exacerbations of COPD which result in hospital admission: a systematic review
}

This article was published in the following Dove Press journal:

International Journal of COPD

29 March 2014

Number of times this article has been viewed

\section{Alison Pooler ${ }^{1,2}$ \\ Roger Beech ${ }^{2}$}

'School of Nursing and Midwifery, Clinical Education Centre, University Hospital of North Staffordshire NHS Trust, Stoke-on-Trent, UK; ${ }^{2}$ Health Services Research, Research Institute of Primary Care and Health Sciences, Keele University, Keele, UK
Correspondence: Alison Pooler School of Nursing and Midwifery, Research Institute of Primary Care and Health Sciences, Clinical Education Centre, University Hospital of North Staffordshire NHS Trust,

Stoke-on-Trent, ST4 6QG, UK

Tel +44 I782679659

Email a.pooler@keele.ac.uk
Objectives: Exacerbations of chronic obstructive pulmonary disease (COPD) are the third largest cause of emergency hospital admissions in the UK. This systematic literature review explored the relationship between the hospitalization rates and the COPD comorbidities, anxiety, and depression.

Methods: The Centre for Research Dissemination's framework for systematic reviews was followed using search terms relating to COPD, anxiety, depression, and hospital admission. Papers identified were assessed for relevance and quality, using a suitable Critical Appraisal Skills Programme tool and Mixed Methods Assessment Tool.

Results: Twenty quantitative studies indicated that anxiety and depression led to a statistically significant increase in the likelihood of COPD patients being hospitalized. These comorbidities also led to an increased length of stay and a greater risk of mortality postdischarge. Other significant factors included lower Body-Mass Index, Airflow Obstruction, Dyspnea, and Exercise scores, female gender, lower socioeconomic status, poorer patient perceived quality of life, increased severity of lung function, and less improvement in dyspnea from admission to discharge. It was also highlighted that only $27 \%-33 \%$ of those with depression were being treated for it. Four qualitative studies revealed that patients saw anxiety and depression as a major factor that affected their ability to cope with and self-manage their condition.

Implications: Findings from the systematic review have highlighted a need for better recognition and treatment of anxiety and depression amongst individuals with COPD. Ongoing research will develop and test strategies for promoting better management and self-management as a means of reducing hospital admissions.

Keywords: COPD, exacerbations, depression, anxiety, hospital admissions

\section{Background}

Chronic obstructive pulmonary disease (COPD) is a major cause of chronic morbidity and mortality worldwide. The 2002 World Health Report ${ }^{1}$ listed COPD as the fifth leading cause of death in the world. Further increases in its prevalence and mortality are expected to make it the third leading cause of mortality by $2015 .^{2,3}$ COPD is a complex disease, triggered mostly by exposure to cigarette smoking. It leads not only to pulmonary damage but also to systemic impairment. There is also a growing awareness of systemic inflammation, cardiovascular, neurologic, psychiatric, and endocrine morbidities that are common comorbidities of the condition and have a long-term detrimental effect on the morbidity and mortality of COPD patients. ${ }^{4,5}$

COPD has a major effect on the lives of the sufferers, particularly in terms of impaired exercise performance and functional capacity. The presence of daily 
symptoms and a high exacerbation frequency are other important factors. ${ }^{6}$ COPD also accounts for many visits to health care professionals in the UK. General practitioner consultations for COPD in one year range from 4.17 per 1,000 consultations in people aged $45-64$ years to 8.86 per 1,000 in $65-74$ years to 10.32 per 1,000 in $75-84$ year olds. ${ }^{7-9}$ These rates are four times those for the chest pain caused by ischemic heart disease. Exacerbations are also an important cause of hospitalization and are responsible for about $10 \%$ of all acute medical admissions. ${ }^{10,11}$ They are also the second largest cause of unplanned hospital admissions ${ }^{12}$ and strongly influence the health-related quality of life for the sufferer. ${ }^{5,13-15}$

Donaldson et $\mathrm{a}^{16}$ demonstrated that the frequency of the occurrence of the acute exacerbations contributed to long-term decline in lung function in COPD. They showed that patients with COPD who suffered frequent exacerbations experienced a significantly greater decline in forced expiratory volume in 1 second $\left(\mathrm{FEV}_{1}\right)$ than patients who had infrequent exacerbations. Exacerbations are more common than previously believed (2.5-3 per year [mean]). ${ }^{13}$ Also, following an exacerbation, the incomplete recovery of lung function after the event means that the patient may not regain his or her stable lung function, which may contribute to a decline in lung function with time, which is characteristic of COPD. ${ }^{14-16}$ These findings emphasize the importance of targeting COPD exacerbations to reduce disease progression and, particularly, to detect patients who are frequent exacerbators and the underlying factors that contribute to these exacerbations.

Anxiety and depression are common comorbidities of COPD. ${ }^{17-19}$ The literature also suggests that there may be a relationship between these comorbidities and the exacerbations of COPD ${ }^{20}$ This literature is not, however, conclusive ${ }^{21,22}$ due to: different tools being used to measure anxiety and depression; studies being conducted in different countries that have noncomparable health services; and some studies that include asthmatics, as well as people with COPD. Untreated or incompletely treated depression and anxiety may also have major implications for compliance with medical treatment, due to the effects on cognitive functioning and the decreased effectiveness of any self-management activities that the person may instigate. ${ }^{23-25}$ The way in which anxiety and depression may be associated with COPD exacerbations may also have a relationship with this issue of ineffective coping and selfmanagement strategies adopted by the patients. Depression may also be a significant predictor of mortality following hospitalization for acute exacerbation. ${ }^{26}$

\section{Aim and objectives}

In this paper, we wanted to examine critically the relationship between anxiety/depression and the exacerbations of COPD that result in hospital admission and readmissions and to investigate whether there are other mediating factors involved.

\section{Objectives}

Our objectives were: 1) to clarify the evidence base available regarding the relationship between anxiety/depression and the exacerbations of COPD that lead to hospital admissions and readmissions; and 2) to identify any other factors that might lead to the hospitalization following an exacerbation of COPD patients with the comorbidities of anxiety and depression. These other factors may also include the ability to cope and to self-manage their condition, as well as other comorbidities and social factors.

\section{Materials and methods}

A systematic review of the literature was carried out following the University of York's Centre for Reviews and Dissemination's (CRD) guidance. ${ }^{27}$ The review question was framed in terms of population, investigation, outcome, and study design (PIOS), with the population being anyone with COPD - any age, any gender, and any severity. The conclusion of the investigation was that these people had the comorbidities of anxiety and/or depression, and the outcome was admission to the hospital for the exacerbation of COPD.

The study design for the research studies sourced was not specified and not restricted by date or place where the study was carried out; this was done so as not to restrict the review. The inclusion criteria for the review were studies relating to having COPD and the comorbidities of anxiety and depression and patients being admitted to the hospital with an acute exacerbation of COPD.

Initially, the Cochrane Review database was searched to ensure that a similar review had not already been carried out nor was it in the process of being conducted. Electronic databases were then searched to elicit literature relevant to the review question set. These electronic databases included PubMed/Medline, Cumulative Index to Nursing and Allied Health Literature, Embase, Web of Science, and PsycINFO. The search terms were broken down in terms of PIOS and outlined in Table 1.

Following the searches of these individual areas that used OR to combine all the terms, the population search terms were then combined with the outcome search terms with OR; they were then further combined with the intervention search 
Table I Search terms used in the electronic database search

\begin{tabular}{|c|c|c|}
\hline PIOs component & $\begin{array}{l}\text { Search terms used (including MeSH, } \\
\text { thesaurus, truncated terms) }\end{array}$ & How search terms were combined \\
\hline Population (having COPD) & $\begin{array}{l}\text { COPD; COAD; chronic obstructive } \\
\text { pulmonary disease; chronic obstructive } \\
\text { airways disease; bronchial disorders; } \\
\text { pulmonary emphysema; pulmonary disease }\end{array}$ & \#I combined terms for Population with OR \\
\hline $\begin{array}{l}\text { Investigation (having } \\
\text { comorbidities of anxiety } \\
\text { and/or depression) }\end{array}$ & $\begin{array}{l}\text { anxi*; anxiety; anxiety disorders; acute } \\
\text { anxiety; depress*; depressive disorder; } \\
\text { depression; depressive episode }\end{array}$ & $\begin{array}{l}\text { Combines search \#6 with search terms for anxiety with AND } \\
(\# 7) \text { (this gave final articles for anxiety); combined search \#6 } \\
\text { with search terms for depression with AND (\#8) (this gave } \\
\text { final articles for depression) }\end{array}$ \\
\hline $\begin{array}{l}\text { Outcomes (having an } \\
\text { exacerbation of COPD and } \\
\text { being admitted to hospital) }\end{array}$ & $\begin{array}{l}\text { Exacerbat*; disease exacerbation; disease } \\
\text { progression; admission; hospital admission; } \\
\text { hospitalization; hospital discharge }\end{array}$ & $\begin{array}{l}\# 2 \text { combined search \#I with terms for exacerbation with OR } \\
(\# 3) \text {; \#4 combined search \#I with terms for hospital admissions } \\
\text { with OR (\#5); then, combined search \#3 with \#5 with OR } \\
\text { (COPD, exacerbations and hospital admission searches) (\#6) }\end{array}$ \\
\hline
\end{tabular}

Abbreviations: PIOs, population, investigation, outcome, and study design; MeSH, medical subject headings; COPD, chronic obstructive pulmonary disease; COAD, chronic obstructive airways disease.

terms, using the search words "anxiety" and "depression" separately - combining with AND for the final outcome of the searching.

Other potential research papers were identified from the reference lists of the articles read in full text for the final review. Abstracts from relevant conferences that were identified by the database searches were also reviewed, and authors were contacted for further information on relevant abstracts. This extra clarification and checking process has been identified by the $\mathrm{CRD}^{27}$ as good practice to ensure a complete inclusion of relevant data.

The selection of the studies retrieved from the electronic searching was done in distinct stages. Initially, all duplications were removed. Then, the titles and abstracts were reviewed against the inclusion criteria for the review. Remaining articles were then screened by reading the full text, which then left the remaining articles to be reviewed in a final review (Figure 1). Two researchers reviewed the full-text articles to decide on the final articles to be included. A third reviewer was available to resolve any disagreements that occurred in this process. This peer review was also carried out during the data extraction stage of the review.

The systematic review of the literature was carried out May 2012-September 2012. It should be stressed however that although the last search was run at the end of September 2012, an alert system was set up on the electronic search databases to highlight any new research being published that may have had relevance to the search area topic. When this paper was submitted for publication, no further research publications had been identified that addressed the question set in this systematic review.

Data extraction was carried out using the Strengthening the Reporting of Observational Studies in Epidemiol- ogy (STROBE) guidelines ${ }^{28}$ for the individual study designs that were included in the final review. The methodology of the articles was reviewed using the appropriate Critical Appraisal Skills Programme tool for critique of literature. $^{29}$

During the data-extraction stage of the review, quality checks were carried out on each individual study to be included in the final systematic review. For this process, the Mixed Methods Appraisal Tool version 2011 (MMAT, Department of Family Medicine, McGill University, Montreal, QC, Canada) was used. ${ }^{30}$

The MMAT has been designed for the appraisal stage of complex systematic literature reviews that include qualitative, quantitative, and mixed methods studies. The MMAT permits the reviewer to appraise concomitantly and describe the methodological quality for the three methodology domains: mixed, qualitative, and quantitative; subdivided into three sub domains; and randomized controlled trials, nonrandomized, and descriptive. The MMAT allows the appraisal of most common types of study methodology and design; different sections of the tools are used for the appraisal of the different study types. For each relevant study selected for a systematic mixed studies review, the methodological quality can then be described using the corresponding criteria. The MMAT has been designed to appraise the methodological quality of the studies retained for a systematic mixed studies review, not the quality of their reporting (writing). This distinction is important - as good research may not be well-reported.

The scoring metrics for the MMAT can be presented as $*, * *, * * *$, or $* * * *$, where the $*$ represents the number of criteria met, divided by 4 . This becomes: the single * represents 


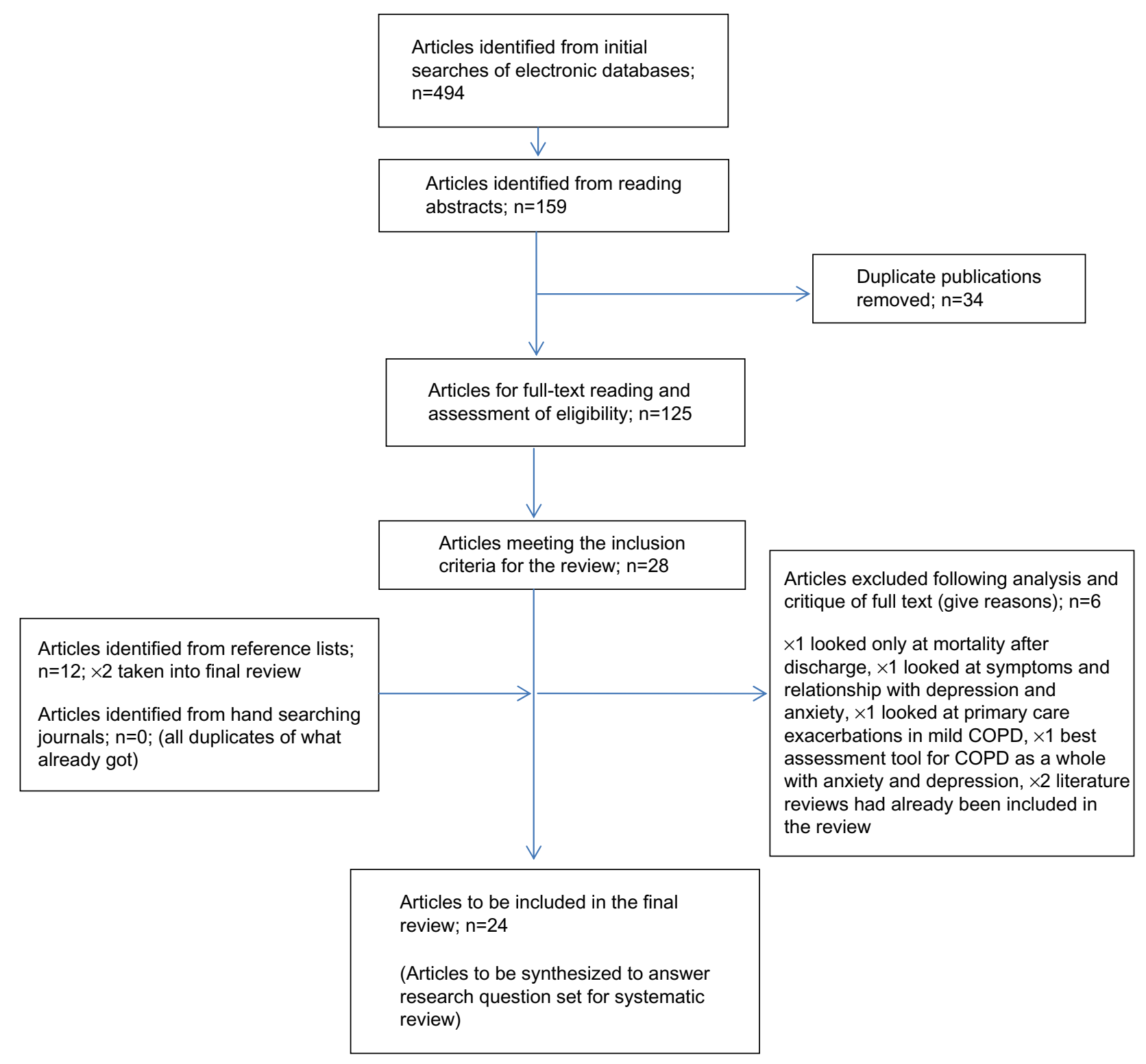

Figure I Flow chart of study selection process.

Abbreviation: COPD, chronic obstructive pulmonary disease.

$25 \%$; the $* *, 50 \%$; the $* * *, 75 \%$; and the $* * * *, 100 \%$, and represents top quality.

Due to the heterogeneity of the final articles included in the review, the methodology chosen for the synthesis of the findings was via narrative synthesis, using the guidance developed by Popay et $\mathrm{al}^{31}$ to provide some structure and transparency of the results generated.

\section{Method of synthesis}

"Narrative synthesis" refers to an approach to the systematic review - the synthesis of findings from multiple studies that relies primarily on the use of words and text to summarize and explain the findings of the synthesis. ${ }^{31}$
The narrative synthesis guidance ${ }^{31}$ identifies four elements of the process of narrative synthesis: 1) developing a theory of how the intervention works, why, and for whom; 2) developing a preliminary synthesis; 3 ) exploring the relationships within and between the studies; and 4) assessing the robustness of the synthesis.

For each element of the synthesis process, the guidance describes a number of useful tools and techniques. The choice of specific tools and techniques at each point in the process will depend on the type of data being synthesized. Only the tools and techniques actually used in this synthesis are described in this article. Figure 2 illustrates the synthesis process. 


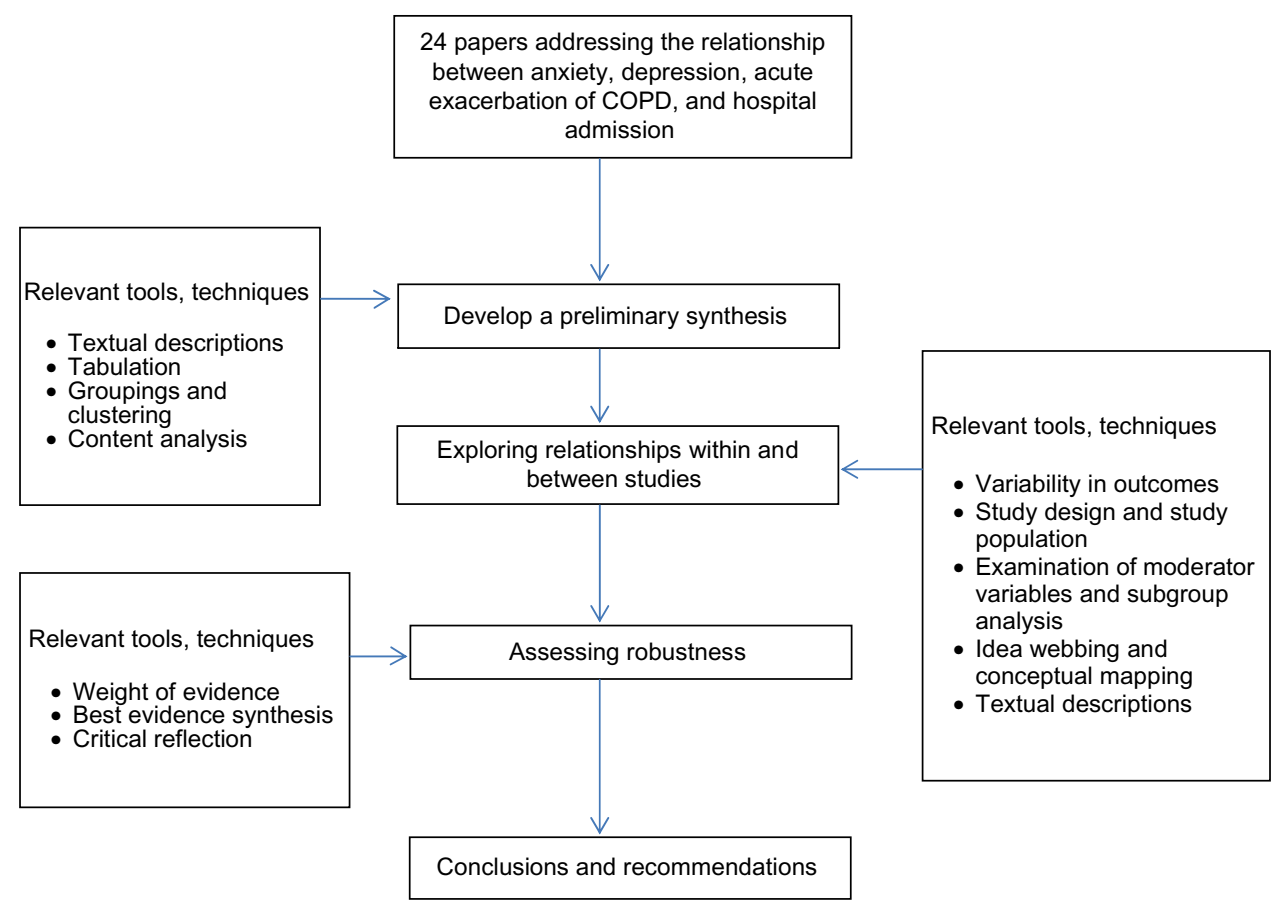

Figure 2 Synthesis process used in the review of the literature.

Abbreviation: COPD, chronic obstructive pulmonary disease.

\section{Results}

\section{Theoretical development}

COPD exacerbations are best defined as the worsening of respiratory symptoms. ${ }^{14}$ More strategies to reduce exacerbation frequency urgently need to be delivered and evaluated. Clinicians will be in a better position to reduce the morbidity associated with COPD exacerbations significantly and - at last - improve the quality of life for our patients with this debilitating condition. Hence, it is important to understand the relationship between the comorbid conditions of anxiety and depression and the acute COPD exacerbations that result in hospital admissions. Theories can then be developed to postulate on such a relationship and other mediating factors involved, but the facts cannot be unveiled without undertaking this systematic review and conducting a thorough and systematic synthesis of the findings. Only then will the nature of this relationship and, indeed, if other factors are involved, be discovered.

Figure 3 illustrates the theoretical relationship between anxiety and depression and the acute exacerbations of COPD that result in admission or readmission to the hospital.

\section{Preliminary synthesis}

The guidance suggests that the way in which a reviewer approaches the preliminary synthesis will depend - in parton whether the evidence to be synthesized is qualitative, quantitative, or both. ${ }^{31}$ In this synthesis, the data to be synthesized is predominantly quantitative from the methodologies of cohort and case control/series nature, amounting to 20 studies.

There were also three qualitative studies and one mixedmethod study. With this in mind, the tools utilized in this preliminary synthesis are textual description, tabulation of data, groupings, and clusters.

The purpose of this preliminary synthesis is to deliver an initial description of the results of the individual studies

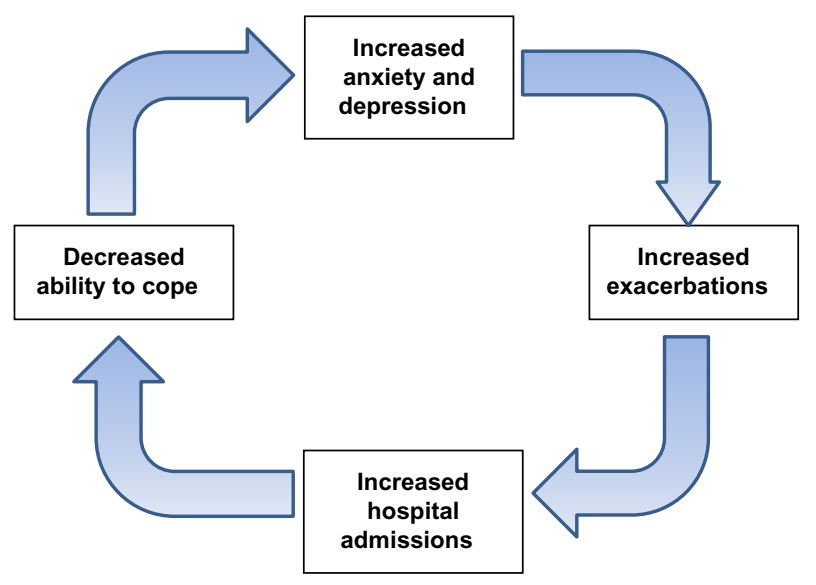

Figure 3 Diagrammatic representation of the theoretical relationship between anxiety and depression and acute exacerbations of COPD that result in hospital admissions or readmission.

Abbreviation: COPD, chronic obstructive pulmonary disease. 
included in the systematic review, which relate to the primary research question asked at the start of the systematic review. Through this, the reviewer will begin to construct an explanation of how and why a particular factor had the relationships reported, of how and why particular factors impinged in situations, and to test the robustness of the results of the synthesis.

Tabulation of data was considered the most natural starting point for the synthesis while extracting data from the included studies during the review process. This is shown in Table 2, which provides a summary of all the studies included in the systematic review.

It is apparent from Table 2 that the majority of the studies directly supported the notion that there was a positive relationship between anxiety and depression and the resultant admissions or readmissions to the hospital for an acute exacerbation of COPD. Findings also highlighted other mediating factors that were involved in this relationship. These included: perceived quality of life; severity of disease; female sex; lower body-mass index, airflow obstruction, dyspnea, and exercise (BODE) scores (an index of COPD mortality; the lower the score, the more chance of death from COPD); low socioeconomic status; persistent smoking; long-term oxygen therapy (LTOT); decreased self-efficacy and compliance; increased dyspnea; a sense of loss; and an inability to cope and previous admissions for acute exacerbation of COPD.

Another important factor demonstrated by the results in Table 2 was the heterogeneity of the studies, in terms of populations, country of origin, sample sizes, statistical tests applied, and outcomes. The data extraction table (Table 2) was examined in more depth to determine the presence of dominant groups or clusters of characteristics, by which the subsequent synthesis could be organized. These groupings incorporated study methodology, populations under study and settings, factors under investigation, and outcomes recorded. Table 2 was organized into the different methodologies. From this, it was apparent that in studies of the same basic methodology, different factors were included in the models under investigation. Some used the measurement of depression and anxiety; some used one of these conditions alone. There was also variation in the tools used to measure these factors.

In addition, some studies used depression and anxiety as secondary outcome measures, with the quality of life and BODE scores as the primary outcome measures under investigation. The end results, though, still yielded information that could contribute to the answering of the research question set at the start of the systematic review.

From comparing and cross reading the included studies in the final systematic review, there is evidence that the comorbidities of depression and anxiety do have a significant relationship with higher rates of admissions and readmissions for the acute exacerbation of COPD. ${ }^{26,32-44}$ This was found in 17 of the final $24(71 \%)$ studies.

Other areas shown from the included studies were that the presence of the comorbidities of depression and anxiety meant that once admitted, patients had longer lengths of stay in the hospital ${ }^{48}$ and a greater risk of mortality postdischarge. $^{20,26,32,41}$

Mediating factors observed to be significant in this relationship between the comorbidities of anxiety, depression, and the acute exacerbation of COPD included: lower BODE scores, ${ }^{19,32,33}$ perceived quality of life, which also had a direct correlation with worsening depression and increased risk of exacerbations; ${ }^{19}$ lower socioeconomic status; ${ }^{37}$ increased severity of anxiety; female sex; ${ }^{19,34,44,45}$ increasing rate of decline in lung function; ${ }^{36}$ less improvement in dyspnea; increased partial pressure of carbon dioxide $\left(\mathrm{PaCO}_{2}\right)$; decreased partial pressure of oxygen $\left(\mathrm{PaO}_{2}\right)$; and increased $\mathrm{pH}$ from admissions to discharge..$^{34,43,46}$

It was also highlighted that only $27 \%-33 \%$ of patients with depression and COPD were being treated with antidepressant medication, which suggests the underdiagnosis and undertreatment of depression in the COPD population. ${ }^{41}$ This proposition - that depression is underdiagnosed ${ }^{41}-$ is also supported by the findings of Fan et al, ${ }^{47}$ who stated that although there is a high prevalence of depression in COPD patients, only $33 \%$ receive any medication for it. There was no data relating to nonpharmacological-management techniques.

Analysis for the qualitative studies, which examined patients' perceptions and subjective experiences, suggested that anxiety should be seen as an important issue for COPD patients. Anxiety might provide an important indicator of actual illness severity and assist clinicians in determining the support and care that these people require. ${ }^{48}$ It is essential, then, that anxiety is recognized as an important sign but not necessarily the cause of dyspnea for patients with COPD in acute exacerbation. It was also highlighted that depression is significantly related to decreased quality of life, which in turn - can lead to decreased compliance, resulting in an increased incidence of exacerbations and the associated risk of mortality on discharge following the exacerbations. ${ }^{41}$ The relationship between depression and lower levels of quality of 


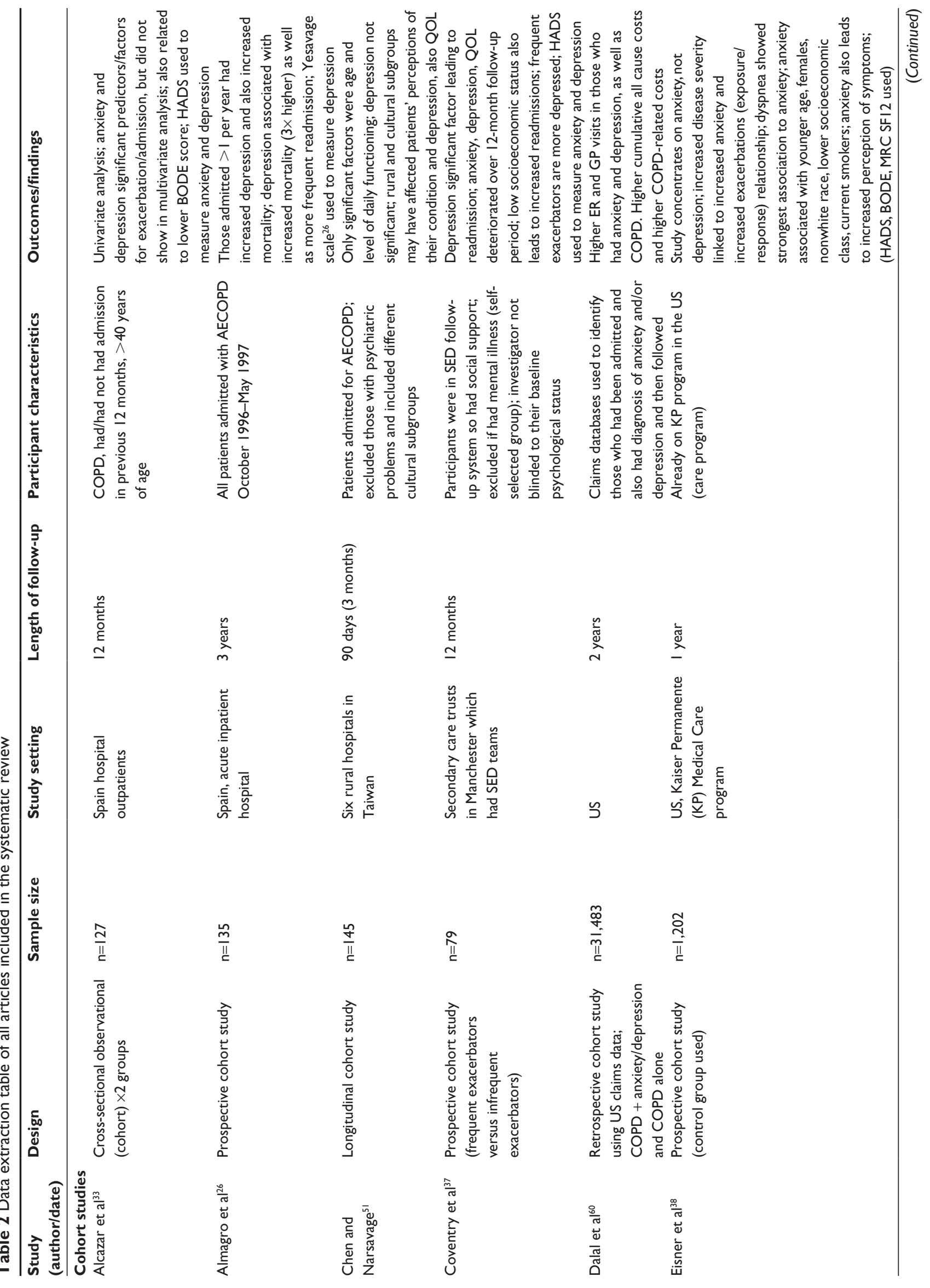




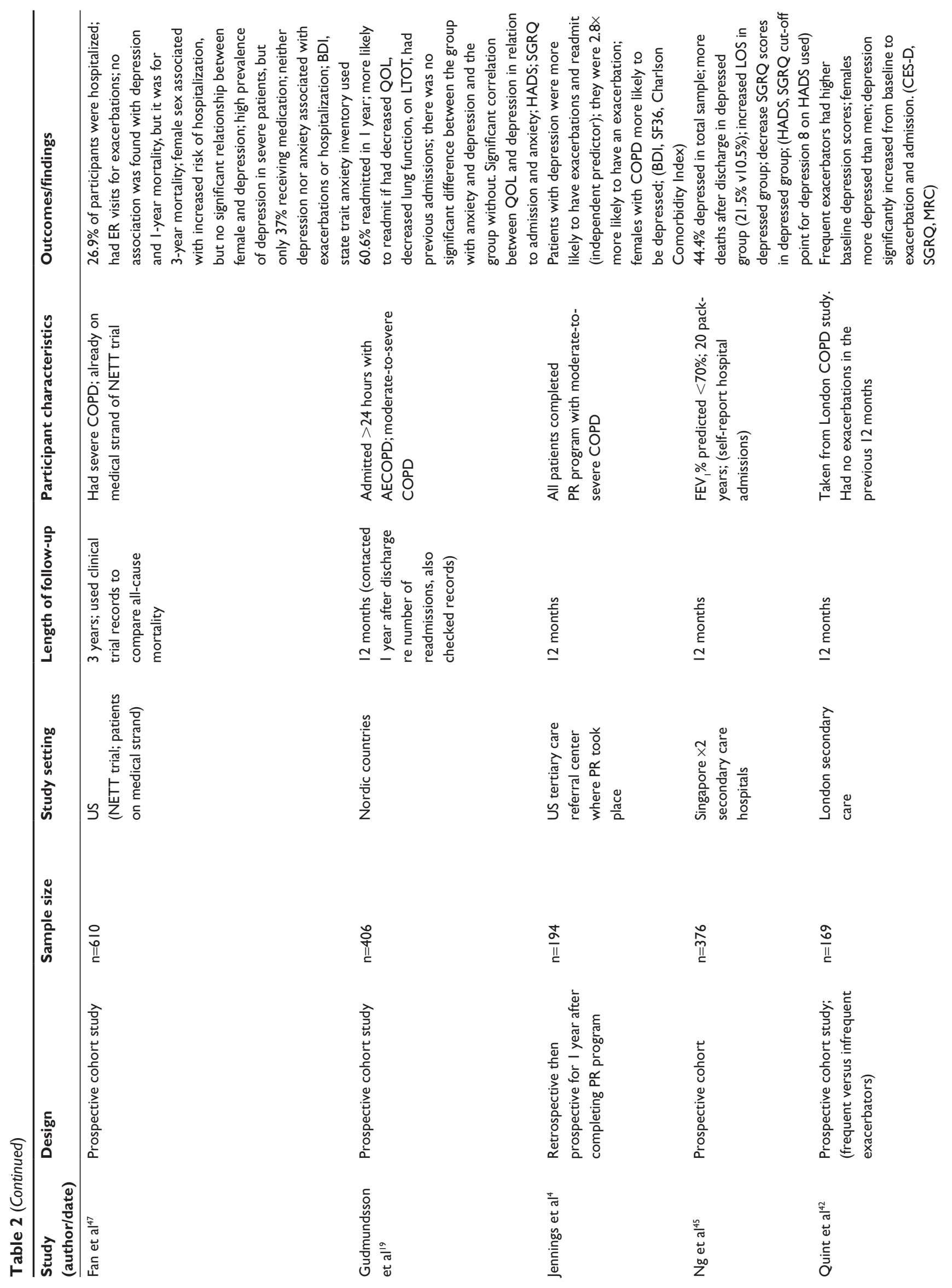



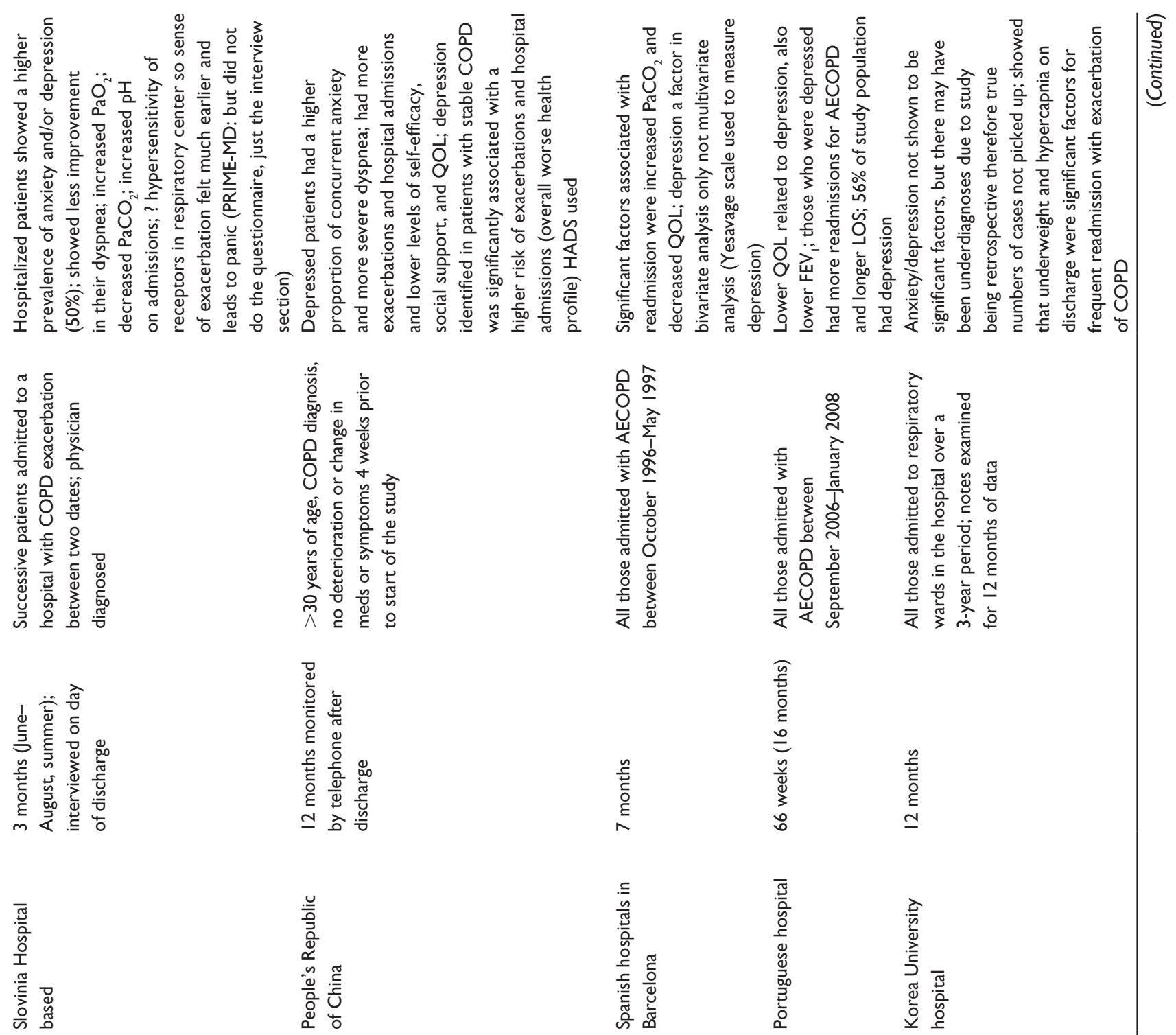

$\stackrel{0}{\text { II }}$

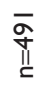

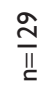
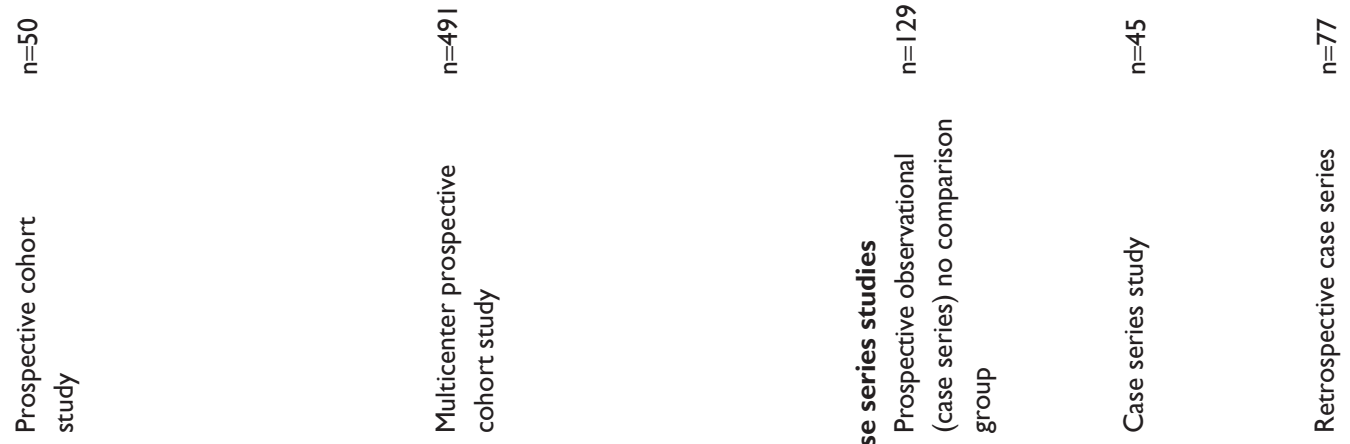

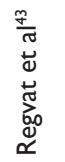

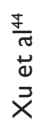
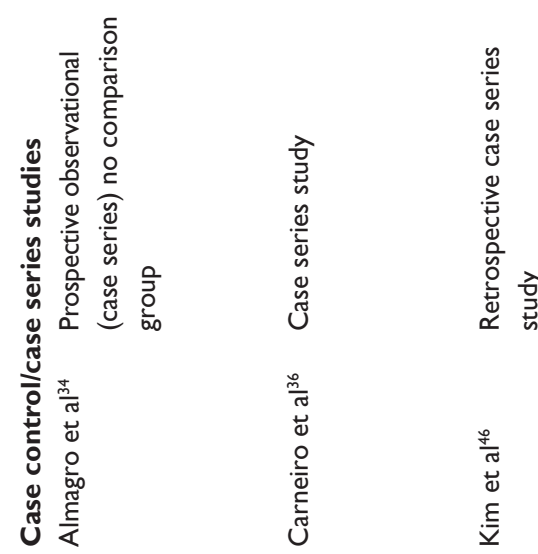


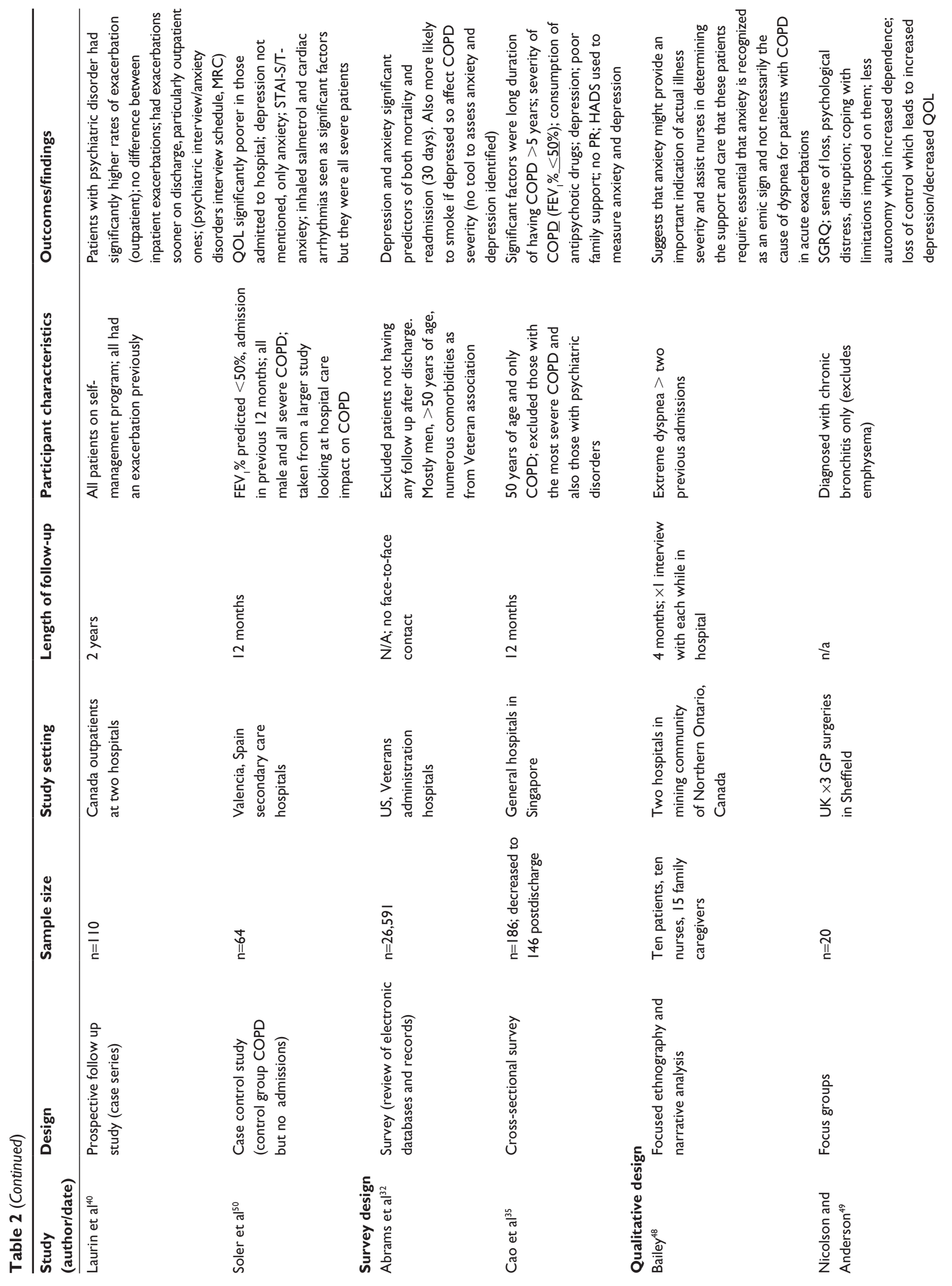




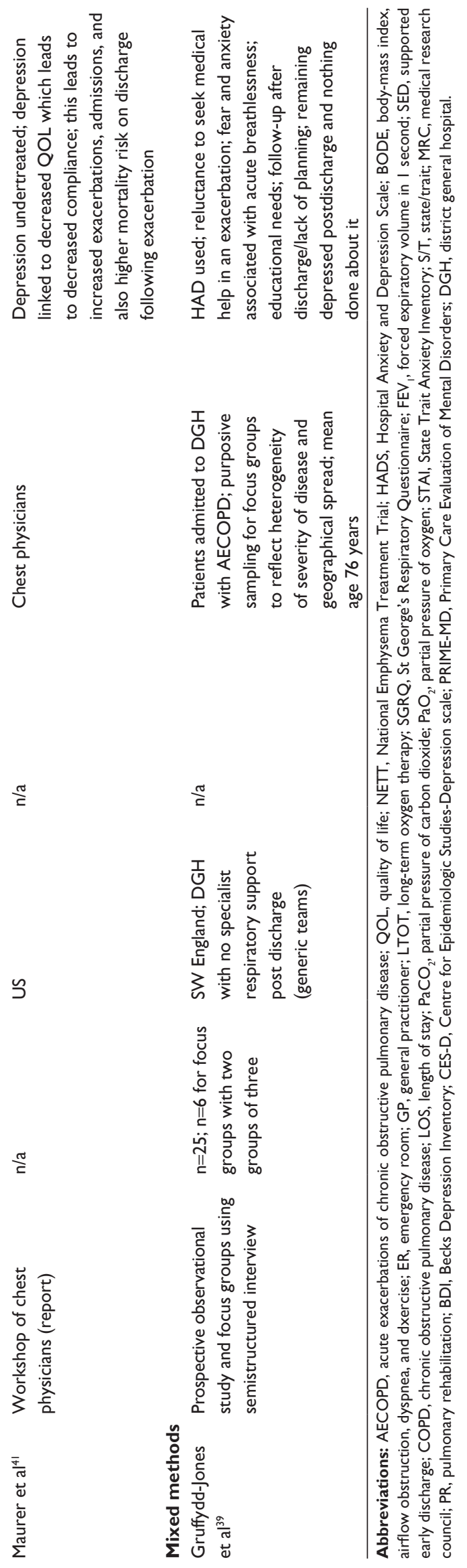

life was also highlighted by Coventry et al, ${ }^{37}$ Gudmundsson et al, ${ }^{19} \mathrm{Ng}$ et al,${ }^{45}$ and $\mathrm{Xu}$ et al. ${ }^{44}$

An examination of the patients' perceptions and experiences in the qualitative and mixed methods studies showed that they felt a real sense of loss of control over their health, which led to an increased dependence and loss of autonomy. ${ }^{52}$ These consequences imposed on the patients also triggered an increase in depression and a resultant decrease in the quality of life. ${ }^{39}$ Their ability to cope was compromised, which again, led to increased levels of anxiety and depression. ${ }^{39}$ These perceptions and experiences were also confounded by the perceived lack of information and guidance given to patients postdischarge, which led to increased levels of anxiety. ${ }^{39}$

It can be seen from this synthesis of the data that the relationship of anxiety and depression to the acute exacerbation of COPD is significant, but it is also complex, multifaceted, and concerns many interrelated factors. These factors build on the preliminary theoretical model shown in Figure 2; the expanded theoretical perspective of this relationship is shown in Figure 4.

It is important to point out that there were two studies which reported that anxiety and depression were not significant factors in the relationship between the exacerbations and the hospital admissions. These two studies were by Soler et $\mathrm{al}^{50}$ and Chen and Narsavage. ${ }^{51}$ On closer examination of these two studies, the study by Chen and Narsavage ${ }^{51}$ was carried out in rural Taiwan. It was acknowledged within the paper itself that rural and cultural subgroups may have different perceptions of their condition, especially of having depression, which is regarded quite negatively by some cultures. This may have affected the perceptions and feedback from the participants about their condition when interviewed and even how they presented to the hospital, as some cultures would suffer at home rather than go to the hospital. It was also noted that the participants would access different hospitals in a wide area, which could make the collection of quality data difficult to achieve.

The study by Soler et a $\mathrm{l}^{50}$ only examined anxiety and although it showed itself to be a significant factor in the relationship under question - depression was excluded. Very often, however, these two conditions were present together in the person. They highlighted that significant factors were the use of inhaled salmeterol (a long-acting bronchodilator inhaler medication) and, also, cardiac arrhythmias.

On a closer examination of the study group characteristics, the majority of participants were on salmeterol at the start of the study, which was not the case in the other studies included in the review. Also, the study group only 


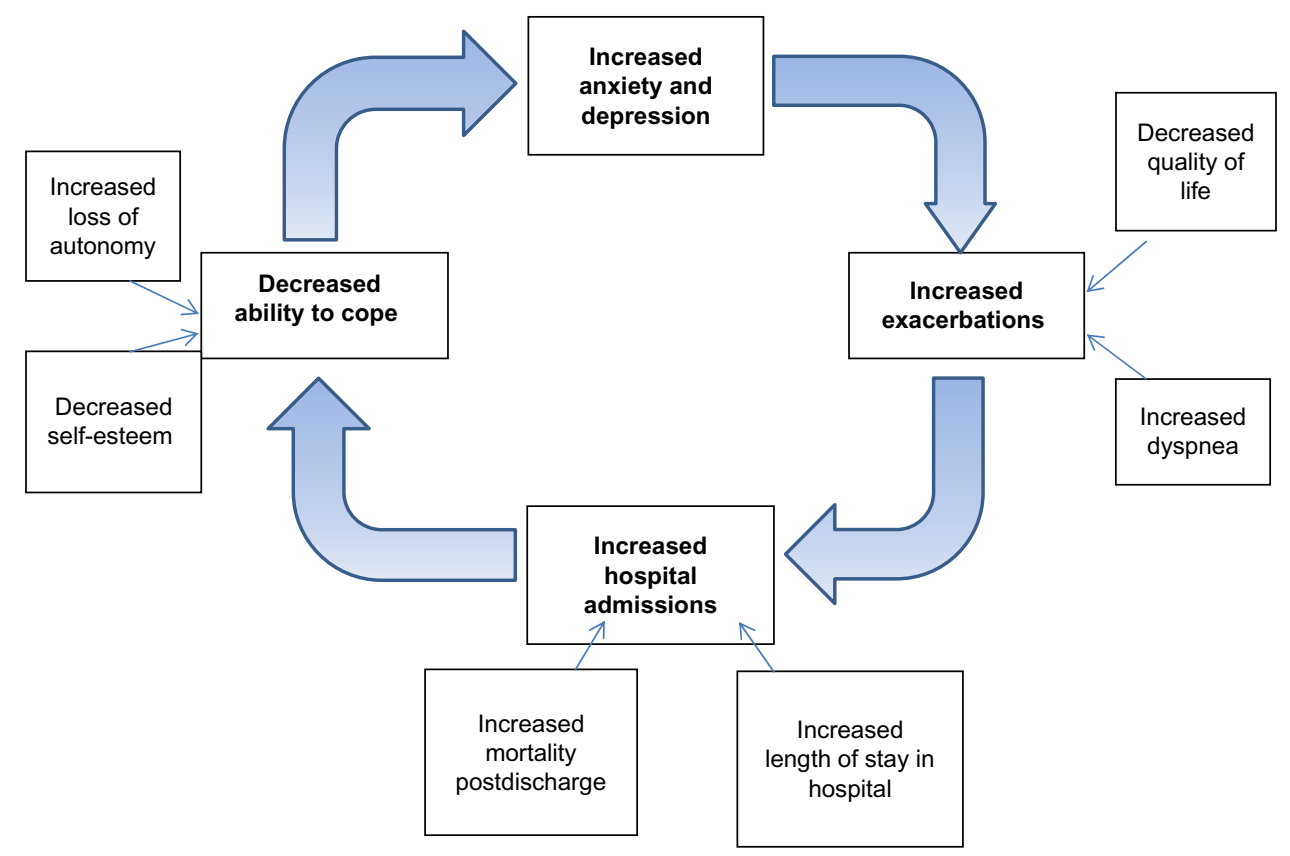

Figure 4 Idea webbing of factors involved in the relationship of anxiety and depression and the acute exacerbation of COPD.

Abbreviation: COPD, chronic obstructive pulmonary disease.

consisted of people with severe COPD, in which cardiac arrhythmias are commonly found as a comorbidity. It is not surprising, therefore, that both of these factors had a higher chance of showing themselves to be significant. Although these findings are relevant if relating the findings to only people with severe COPD, this review is considering the relation of anxiety and depression to acute exacerbations and resultant hospital admissions and readmissions to the general COPD population, which the other studies in the review consider.

This model (Figure 4) builds on the original theory of the relationship between anxiety and depression and the exacerbations of COPD. The additional variables are those discovered from the systematic review of the literature, and they enhance the preliminary theoretical model further in the quest to gain a deeper understanding of the relationship under review.

Finally, during the process of data extraction, quality checks on the methodology of all the included articles in the review were carried out using the MMAT version 2011. ${ }^{30}$ Quality appraisal of all the included studies in this systematic review showed that 16 of 24 ( $66 \%$ or two-thirds) had a $* * * *$ rating. Therefore, they met $100 \%$ of the quality criteria, and eight (33\% or one-third) had a quality rating of $* * *$. Therefore, they met $75 \%$ of the quality criteria used, a number that was still symbolic of high-quality studies. The reasons for the drop in the star rating to three stars were: because there was no information about the missing data or the dropout rate of the participants $(n=6)$; invalid tools were used to measure the outcomes ( $\mathrm{n}=1)$; and there was no consideration of how the researcher involved in the study influenced the participants $(n=1)$. Overall, the quality of the included studies in this systematic review was of high, if not good, quality - meeting between $75 \%-100 \%$ of the quality criteria in the MMAT evaluation tool.

\section{Reflecting critically on the process of narrative synthesis}

The synthesis of mixed study results does not have the rigorous techniques and tools that are available to meta analysis. This is not to say that the quality of the content and results of the systematic review are any less valuable. The question that was originally identified lent itself to both qualitative and quantitative study results; this is why the inclusion criteria were kept wide.

The problem with the narrative synthesis up until now has been that there was no standard way in which the literature was synthesized. It was left to the personal preference and also to the experience of the reviewers; therefore, transparency and rigor could be arguably flawed. The guidance on the narrative synthesis ${ }^{31}$ helps to enhance the quality and transparency of narrative synthesis and, hence, why it was chosen for the synthesis stage of the overall systematic review. The amount of methodological 
heterogeneity in the studies included in the final systematic review also led to the decision to undertake such a method of synthesis.

The levels of bias were reduced by having a second reviewer (an experienced qualitative researcher) at the selection and data extraction stages of the systematic review; this reviewer also reviewed the narrative synthesis once completed. It was also reviewed by an expert in the field of narrative synthesis and one of the main authors of the narrative synthesis guidance. This peer review process aimed to reduce any possible bias that may have resulted if the whole process had been undertaken single-handed.

\section{Discussion}

For decades, the psychiatric morbidity of medically ill patients has been acknowledged. However, there has been relatively little focus on psychiatric disorders in patients with COPD, except for prevalence studies. ${ }^{41,52}$ The results of this systematic review have highlighted a relationship between anxiety and depression and the admission to the hospital with acute exacerbations of COPD. It has also been observed that more evidence is needed to substantiate the evidence further.

COPD is a severe and irreversible pulmonary disease that impacts the patient's general physical condition, functioning, and quality of life. ${ }^{53}$ COPD patients constitute a substantial part of the medically ill patients, both in hospital wards and in outpatient clinics. They present a considerable challenge to the health care system. ${ }^{3,46,54}$

The association between COPD and psychiatric disorders - in particular generalized anxiety, panic disorder, and depression - has been acknowledged for many years. The prevalence of psychiatric comorbidity in these patients, as well as the effect of treatment and the prognosis, remains unclear. The diagnostic procedure is complicated by an overlap or close association of somatic and psychiatric symptoms in COPD patients who suffer from comorbid anxiety and depression.

Caring for such an irreversible condition is challenging, with the most important task being not to cure but to optimize the quality of life of the individual patients. ${ }^{54}$ The quality of life of a chronically ill patient may be particularly complicated by a concurrent depressive disorder that may bring the patient into a vicious circle. The depressed mood will lower the ability needed to cope with the chronic disease. The physical symptoms will then become less tolerable, and the psychosocially debilitating effect of the disease may be enforced by the depressed mood. ${ }^{55,56}$
The impact of anxiety and depression on COPD patients, their families, and society is significant. Depressed patients with a chronic medical illness are usually sicker than their counterparts $^{55,57}$ and have lower treatment adherence. ${ }^{56,58,59}$ Depression adversely affects physical functioning in people with COPD, such as a reduced 12-minute walk distance. ${ }^{56}$ By compromising health status, mood disorders may lead to an increased risk of hospitalization ${ }^{20}$ and rehospitalization. ${ }^{19}$ Depression may also be a significant predictor of mortality following hospitalization for acute exacerbation. ${ }^{26}$

Exacerbations of COPD cause morbidity, hospital admissions, and mortality; they strongly influence health-related quality of life. ${ }^{13}$ Physiological recovery after an exacerbation is often incomplete, which decreases the health-related quality of life and resistance to future exacerbations. It is important to identify COPD patients who suffer from frequent exacerbations.

More strategies to reduce exacerbation frequency urgently need to be delivered and evaluated. We will then, as clinicians, be in a better position to reduce the morbidity associated with COPD exacerbations significantly and, at last, improve the quality of life of patients with this debilitating condition. Therefore, there is a need to understand the relationship of the comorbid conditions of anxiety and depression to COPD and the acute exacerbation that results in hospital admissions, and a need to determine if there are any other factors involved. This systematic review has highlighted that there is a relationship between anxiety and depression and an increased number of exacerbations, resulting in hospital admission for people with COPD. This relationship, however, is not a simple linear one; many other mediating factors have also been discovered. It has also highlighted the heterogeneity of the evidence base that is currently available and the need for a more consistent approach in future research strategies to address this area of clinical importance so that clinical decision making can be made with accuracy.

\section{Conclusion}

Following the synthesis of the data from the systematic review to answer the question "what is the relationship of anxiety and depression to the exacerbations of COPD and the resultant admissions/readmissions to hospital, and are there any other mediating factors involved," the concluding remarks are:

1. Some literature supported the fact that anxiety and depression were significant factors in patients' admissions and readmissions to the hospital following an acute exacerbation of COPD. 
2. The literature also highlighted other significant factors in the relationship between anxiety, depression, and the acute exacerbation of COPD resulting in admission and readmission to hospital. These factors included: reduced quality of life; increasing severity of disease; female gender; lower BODE scores; low socioeconomic status; persistent smoking; increased dyspnea; $\mathrm{PaCO}_{2}$ and decreased $\mathrm{PaO}_{2}$ from admission to discharge; LTOT; sense of loss and inability to cope; decrease in selfefficacy and compliance with treatment; and previous admissions for acute exacerbation of COPD.

Although this goes some way to answering the research question set at the start of the systematic review, for any significant changes to be implemented into clinical practice, further research needs to be carried out. The examination of literature review indicated several implications for the conduct of research in this area; and further research should consider using standardized tools to measure the outcomes, using more comparative study participants and not just men, or groups of COPD patients who were already involved in another study about their disease state. Some studies in this systematic review were done in different countries with different cultural groups who have differing beliefs about diseases. This was discussed by these study authors as being a significant confounding factor; future research should consider and accommodate for this in study design and methodology.

This systematic review was a preliminary review of the literature into this important area of clinical care. Managing depression and anxiety starts with an accurate diagnosis. Many COPD patients have transitory mood symptoms during exacerbations that improve spontaneously as their physical state improves. The challenge is: to identify those who have more permanent and sustained anxiety and depression; to develop ways of screening for and then implementing effective management strategies to alleviate the impact of these comorbidities; and to enable them to cope better with their COPD. The end result should be a reduction in the number of exacerbations that result in unplanned admissions to hospital, which have a devastating effect on the patients and their families.

\section{Disclosure}

The authors report no conflicts of interest in this work.

\section{References}

1. World Health Organization. World Health Report. Geneva: World Health Organization; 2002. Available from: http://www.who.int/whr/2002. Accessed September 29, 2013.
2. Murray CJ, Lopez AD. Alternative projections of mortality and disability by cause, 1990-2020: Global Burden of Disease Study. Lancet. 1997;349(9064):1498-1504.

3. Department of Health. An Outcomes Strategy for Chronic Obstructive Pulmonary Disease (COPD) and Asthma in England. London: Her Majesty's Stationery Office; 2011. Available from: https://www.gov. uk/government/uploads/system/uploads/attachment_data/file/216139/ dh_128428.pdf. Accessed September 29, 2013.

4. Jennings JH, Digiovine B, Obeid D, Frank C. The association between depressive symptoms and acute exacerbations of COPD. Lung. 2009;187(2):128-135.

5. Barnes PJ, Celli BR. Systemic manifestations and comorbidities of COPD. Eur Respir J. 2009;33(5):1165-1185.

6. Ozkaya S, Findik S, Atici AG. The cost of hospitalization in patients with acute exacerbation of chronic obstructive pulmonary disease. Clinicoecon Outcomes Res. 2011;3:15-18.

7. Calverley P. PMPA. (1998). COPD; the key facts. London; BLF

8. Pauwels RA, Rabe KF. Burden and clinical features of chronic obstructive pulmonary disease (COPD). Lancet. 2004;364(9434):613-620.

9. Calderón-Larrañaga A, Carney L, Soljak M, et al. Association of population and primary healthcare factors with hospital admissions rates for chronic obstructive pulmonary disease in England; national cross-sectional study. Thorax. 2011;66(3):191-196.

10. Miravitlles M, Murio C, Guerrero T, Gisbert R; DAFNE Study Group; Decisiones sobre Antibioticoterapia y Farmacoeconomía en la EPOC. Pharmacoeconomic evaluation of acute exacerbations of chronic bronchitis and COPD. Chest. 2002;121(5):1449-1455.

11. Roberts CM, Stone RA, Lowe D, Pursey NA, Buckingham RJ. Co-morbidities and 90-day outcomes in hospitalized COPD exacerbations. COPD. 2011;8(5):354-361.

12. Royal College of Physicians, British Thoracic Society, British Lung Foundation. Report of the National Chronic Obstructive Pulmonary Disease Audit 2008; Clinical Audit of COPD Exacerbations Admitted to Acute NHS Units Across the UK. London: The Health Foundation; 2008. Available from: http://www.rcplondon.ac.uk/sites/default/files/ report-of-the-national-copd-audit-2008-resources-and-organisationof-care-in-acute-nhs-units-across-the-uk.pdf. Accessed September 29, 2013.

13. Wedzicha JA, Donaldson GC. Exacerbations of chronic obstructive pulmonary disease. Respir Care. 2003;48(12):1204-1213; discussion 1213-1215.

14. Wedzicha JA, Seemungal TA. COPD exacerbations: defining their cause and prevention. Lancet. 2007;370(9589):786-796.

15. Seemungal TA, Donaldson GC, Bhowmik A, Jefferies DJ, Wedzicha JA. Time course and recovery of exacerbations in patients with chronic obstructive pulmonary disease. Am J Respir Crit Care Med. 2000; 161(5):1608-1613.

16. Donaldson GC, Seemungal TA, Bhowmik A, Wedzicha JA. Relationship between exacerbation frequency and lung function decline in chronic obstructive pulmonary disease. Thorax. 2002;57(10);847-852.

17. Andenaes R, Kalfoss MH, Wahl A. Psychological distress and quality of life in hospitalized patients with chronic obstructive pulmonary disease. J Adv Nurs. 2004;46(5):523-530.

18. Yohannes AM, Baldwin RC, Connolly MJ. Predictors of 1-year mortality in patients discharged from hospital following acute exacerbation of chronic obstructive pulmonary disease. Age Ageing. 2005;34(5): 491-496.

19. Gudmundsson G, Gislason T, Janson C, et al. Risk factors for rehospitalisation in COPD: role of health status, anxiety and depression. Eur Respir J. 2005;26(3):414-419.

20. Fan VS, Curtis JR, Tu SP, McDonell MB, Fihn SD; Ambulatory Care Quality Improvement Project Investigators. Using quality of life to predict hospitalisation and mortality in patients with obstructive lung diseases. Chest. 2002;122(2);429-436.

21. Garcia-Aymerich J, Farrera E, Félez MA, Izquierdo J, Marrades RM, Antó JM; Estudi del Factors de Risc d'Agudització de la MPOC investigators. Risk factors of readmission to hospital for a COPD exacerbation: a prospective study. Thorax. 2003;58(2):100-105. 
22. Peruzza S, Sergi G, Vianello A. Chronic obstructive pulmonary disease (COPD) in elderly subjects: impact on functional status and quality of life. Respir Med. 2003;97(6):612-617.

23. Bosley CM, Corden ZM, Rees PJ, Cochrane GM. Psychological factors associated with use of home nebulized therapy for COPD. Eur Respir J. 1996;9(11):2346-2350.

24. Kunik ME, Roundy K, Veazey C. Surprisingly high prevalence of anxiety and depression in chronic breathing disorders. Chest. 2005;127(4): 1205-1211.

25. Gudmundsson C, Gislason T, Janson C. Depression, anxiety and health status after hospitalisation for COPD: a multicentre study in the Nordic countries. Respir Med. 2006;100(1):87-93.

26. Almagro P, Calbo E, Ochoa de Echagüen A. Mortality after hospitalization for COPD. Chest. 2002;121(5):1441-1448.

27. Centre for Reviews and Dissemination. Systematic Reviews: CRD's Guidance for Undertaking Reviews in Health Care. Layerthorpe: York Publishing Services Ltd; 2009. Available from: http:/www.york.ac.uk/ inst/crd/pdf/Systematic_Reviews.pdf. Accessed September 29, 2013.

28. von Elm E, Altman DG, Egger M, Pocock SJ, Gøtzsche PC, Vandenbroucke JP; STROBE Initiative. The Strengthening the Reporting of Observational Studies in Epidemiology (STROBE) statement: guidelines for reporting observational studies. J Clin Epidemiol. 2008;61(4):344-349.

29. Critical Appraisal Skills Programme. (2013). Retrieved on 19.4.13 from; http://www.casp-uk.net. Accessed September 29, 2013.

30. Pluye P, Robert E, Cargo M, et al. Mixed Methods Appraisal Tool Version 2011. Quebec, Canada: McGill University; 2011. Available from: http://mixedmethodsappraisaltoolpublic.pbworks.com/f/ MMAT\%202011\%20criteria\%20and\%20tutorial\%202011-06-29.pdf. Accessed January 17, 2013.

31. Popay J, Roberts H, Sowden A, et al. Guidance on the Conduct of Narrative Synthesis in Systematic Reviews; A Product from the ESRC Methods Programme. Lancaster, UK: Lancaster University; 2006. Available from: http://www.lancaster.ac.uk/shm/research/nssr/research/dissemination/ publications/NS_Synthesis_Guidance_v1.pdf. Accessed September $29,2013$.

32. Abrams TE, Vaughan-Sarrazin M, Van der Weg MW. Acute exacerbations of chronic obstructive pulmonary disease and the effect of existing psychiatric comorbidity on subsequent mortality. Psychosomatics. 2011;52(5):441-449.

33. Alcázar B, García-Polo C, Herrejón A. Factors associated with hospital admissions for exacerbation of chronic obstructive pulmonary disease. Arch Bronconeumol. 2012;48(3):70-76. Spanish [with English abstract].

34. Almagro P, Barreiro B, Ochoa de Echaguen A, et al. Risk factors for hospital admissions in patients with chronic obstructive pulmonary disease. Respiration. 2006;73(3):311-317.

35. Cao Z, Ong KC, Eng P, Tan NC, Ng TP. (2006). Frequent hospital readmissions for acute exacerbation of COPD and their associated factors. Respirology. 2006;11(2):188-195.

36. Carneiro R, Sousa C, Pinto A, Almeida F, Oliveira JR, Rocha N. Risk factors for readmission after hospital discharge in chronic obstructive pulmonary disease. The role of quality of life indicators. Rev Port Pneumol. 2010;16(5):759-777. Portuguese [with English abstract].

37. Coventry PA, Gemmell I, Todd CJ. Psychosocial risk factors for hospital readmissions in COPD patients on early discharge services: a cohort study. BMC Pulm Med. 2011;11:49.

38. Eisner MD, Blanc PD, Yelin EH. Influence of anxiety on health outcomes in COPD. Thorax. 2010;65(3):229-234.

39. Gruffydd-Jones K, Langley-Johnson C, Dyer C, Badlan K, Ward S. What are the needs of patients following discharge from hospital after an acute exacerbation of chronic obstructive pulmonary disease (COPD)? Prim Care Respir J. 2007;16(6):363-368.

40. Laurin C, Labrecque M, Dupuis G, Bacon SL, Cartier A, Lavoie KL. Chronic obstructive pulmonary disease patients with psychiatric disorders are at greater risk of exacerbations. Psychosom Med. 2009;71(6): $667-674$
41. Maurer J, Rebbapragada V, Borson S, et al; ACCP Workshop Panel on Anxiety and Depression in COPD. Anxiety and depression in COPD: current understanding, unanswered questions, and research areas. Chest. 2008;134(Suppl 4):43S-56S.

42. Quint JK, Baghai-Ravary R, Donaldson GG, Wedzicha JA. Relationship between depression and exacerbations in COPD. Eur Respir J. 2008; 32(1):53-60.

43. Regvat J,ŽmitekA, Vegnuti M, Košnik M, Šuškovič S. Anxiety and depression during hospital treatment of exacerbation of chronic obstructive pulmonary disease. J Int Med Res. 2011;39(3):1028-1038.

44. Xu W, Collet JP, Shapiro S, et al. Independent effect of depression and anxiety on chronic obstructive pulmonary disease exacerbations and hospitalizations. Am J Respir Crit Care Med. 2008;178(9):913-920.

45. Ng TP, Niti M, Tan WC, Cao Z, Ong KC, Eng P. Depressive symptoms and chronic obstructive pulmonary disease: effect on mortality, hospital admission, symptom burden, functional status, and quality of life. Arch Intern Med. 2007;167(1):60-67.

46. Kim HF, Kunik ME, Molinari VA, et al. Functional impairment in COPD patients: the impact of anxiety and depression. Psychosomatics. 2010;41(6):465-471.

47. Fan VS, Ramsey SD, Giardino ND, et al; National Emphysema Treatment Trial (NETT) Research Group. Sex, depression, and risk of hospitalization and mortality in chronic obstructive pulmonary disease. Arch Intern Med. 2007;167(21):2345-2353.

48. Bailey PH. The dyspnea-anxiety-dyspnea cycle: COPD patients'stories of breathlessness: "It's scary when you can't breathe". Qual Health Res. 2004;14(6):760-778.

49. Nicolson P, Anderson P. The patient's burden; physical and psychological effects of acute exacerbations of chronic bronchitis. J Antimicrob Chemother. 2000;45:25-32.

50. Soler JJ, Sánchez L, Román P, Martínez MA, Perpiñá M. Risk factors of emergency care and admissions in COPD patients with high consumption of health resources. Respir Med. 2004;98(4):318-329.

51. Chen YJ, Narsavage GL. Factors related to chronic obstructive pulmonary disease readmissions in Taiwan. West J Nurs Res. 2006;28(1):105-124.

52. Mikkelsen RL, Middelboe T, Pisinger C, Stage KB. Anxiety and depression in patients with chronic obstructive pulmonary disease (COPD). A review. Nord J Psychiatry. 2004;58(1):65-70.

53. Viegi G, Pistelli F, Sherrill DL, Maio S, Baldacci S, Carrozzi L. Definition, epidemiology and natural history of COPD. Eur Respir J. 2007;30(5):993-1013.

54. van Ede L, Yzermans CJ, Brouwer HJ. Prevalence of depression in patients with chronic obstructive pulmonary disease: a systematic review. Thorax. 1999;54(8):688-692.

55. Ciechanowski PS, Katon WJ, Russo JE. Depression and diabetes: impact of depressive symptoms on adherence, function, and costs. Arch Intern Med. 2000;160(21):3278-3285.

56. Felker B, Katon W, Hendrick SC, et al. The association between depressive symptoms and health status in patients with chronic pulmonary disease. Gen Hosp Psychiatry. 2001;23(2):56-61.

57. Sullivan M, Simon G, Spertus J, Russo J. Depression-related costs in heart failure care. Arch Intern Medicine. 2002;162(16):1860-1866.

58. DiMatteo MR, Lepper HS, Croghan TW. Depression is a risk factor for noncompliance with medical treatment: meta-analysis of the effects of anxiety and depression on patient adherence. Arch Intern Medicine. 2000;160(14):2101-2107.

59. Lin EH, Katon W, Von Korff M, et al. Relationship of depression and diabetes self-care, medication adherence, and preventive care. Diabetes Care. 2004;27(9):2154-2160.

60. Dalal AA, Shah M, Lunacsek O, Hanania NA. Clinical and economic burden of depression/anxiety in chronic obstructive pulmonary disease patients within a managed care population. COPD. 2011;8(4):293-299. 
International Journal of COPD

Dovepress

\section{Publish your work in this journal}

The International Journal of COPD is an international, peer-reviewed journal of therapeutics and pharmacology focusing on concise rapid reporting of clinical studies and reviews in COPD. Special focus is given to the pathophysiological processes underlying the disease, intervention programs, patient focused education, and self management protocols.

This journal is indexed on PubMed Central, MedLine and CAS. The manuscript management system is completely online and includes a very quick and fair peer-review system, which is all easy to use. Visit http://www.dovepress.com/testimonials.php to read real quotes from published authors.

Submit your manuscript here: http://www.dovepress.com/international-journal-of-copd-journal 